\title{
Interactions between Economic Growth and Environmental Quality in Shenzhen, China's First Special Economic Zone
}

Xiaozi Liu (xiaoziliu@yahoo.com)

Gerhard K. Heilig (gerhard.heilig@chello.at)

Junmiao Chen

Mikko Heino (mikko.heino@imr.no)

Approved by

Ulf Dieckmann

Program Leader, Evolution and Ecology Program

September 2006 


\section{Contents}

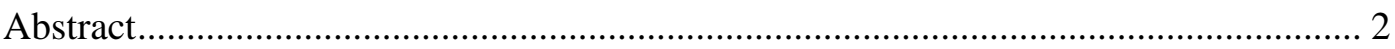

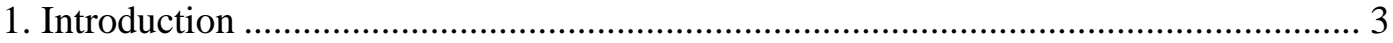

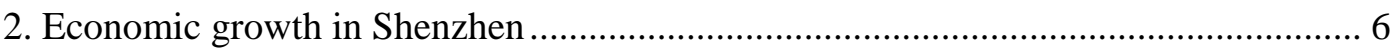

3. The environmental quality trends over time........................................................ 7

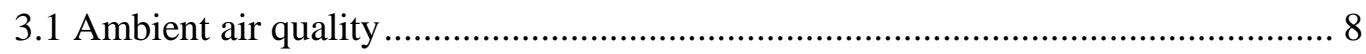

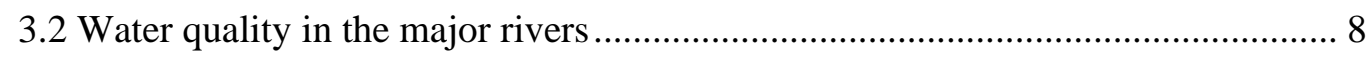

3.3 The near-shore waters quality...................................................................... 10

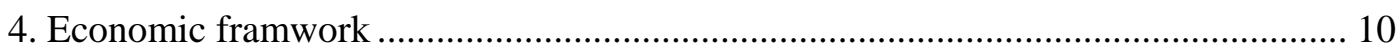

4.1 The regression analysis on ambient air quality ................................................ 11

4.2 The regression analysis on river water quality ................................................ 12

4.3 The regression analysis on near-shore waters ............................................... 13

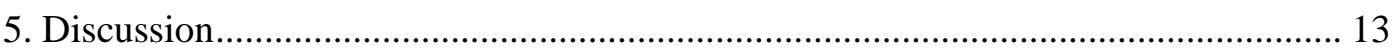

5.1 Production-introduced pollutants support EKC ................................................ 14

5.2 Consumption-related pollutants do not support EKC ........................................ 16

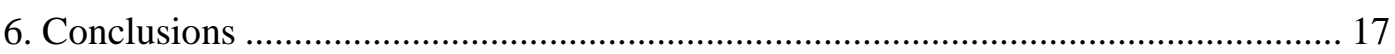

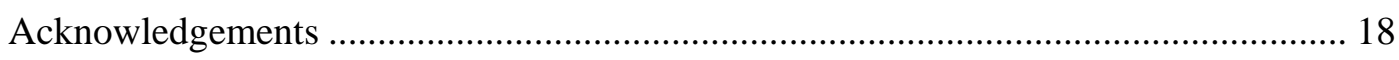

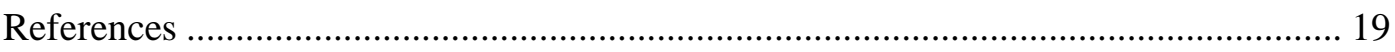

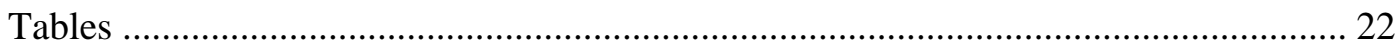

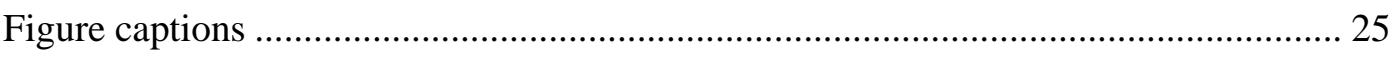




\title{
Interactions between Economic Growth and Environmental Quality in Shenzhen, China’s First Special Economic Zone
}

\author{
Xiaozi Liu ${ }^{\text {a,* }}$, Gerhard K. Heilig', Junmiao Chen ${ }^{c}$, Mikko Heino ${ }^{\text {b,d,e }}$ \\ ${ }^{a}$ Lund University, Lund, Sweden \\ ${ }^{\mathrm{b}}$ International Institute for Applied Systems Analysis (IIASA), Laxenburg, Austria \\ ${ }^{\mathrm{c}}$ Shenzhen Environmental Monitoring Center at Luohu District, Shenzhen, China \\ d Institute of Marine Research, Bergen, Norway \\ ${ }^{\mathrm{e}}$ Institute of Biology, University of Bergen, Norway
}


Abstract: The relationship between economic development and environmental quality is a debated topic. Environmental Kuznets Curve (EKC) is one prominent hypothesis, positing an inverted U-shaped development-environment relationship. Here we test this hypothesis using data from Shenzhen, Peoples Republic of China. Established in 1980 as the first special economic zone in China, Shenzhen has developed from a small village into a large urban-industrial agglomeration with the highest income level in the country. The enormous expansion of infrastructure, industrial sites and urban settlements has profoundly changed the local environment. We utilize environmental monitoring data from Shenzhen on concentration of pollutants in ambient air, main rivers, and near shore waters from 1989 to 2003. The results show that production-induced pollutants support EKC while consumption-induced pollutants do not support it.

Key words: Economic growth, emerging markets, environmental quality, Environmental Kuznets Curve (EKC). 


\section{Introduction}

The People's Republic of China (henceforth China) is the world's most populous country, and also one of the fastest growing economies in the world. Together with its economic impact, China's impact on the global environment is rapidly increasing (Liu and Diamond, 2005), with ramifications that extend for beyond its borders. This paper focuses on environment-development relationships in Shenzhen, the first Chinese Special Economic Zone (SEZ) - in many ways, a pioneer city in both economic development and environmental protection. Shenzhen is thus of special interest in trying to understand the relationships between environmental quality and economic development in China, other emerging markets, and worldwide.

Shenzhen is a natural port city on the border of Hong Kong in south China. Initially, it was a small fishing village. Since being established as the first Chinese Special Economic Zone in 1980, Shenzhen has developed into a substantial urban agglomeration - in less than two decades. The city has had the highest per capita income in China since 1990. Its population has increased from 23,000 inhabitants in the beginning to over 5 million in 2003, mainly due to migration (Sen, 2001; NSB, 2003).

In terms of environmental protection, Shenzhen is regarded as a forefront Chinese city. In 1997, China's State Environmental Protection Agency entitled the city as the first national model city for environmental protection. In 2002, Shenzhen received the United Nations Environment Programme (UNEP) award of Global 500 Roll of Honor due to its efforts to simultaneously yielding both economic and environmental gains 
(UNEP, 2002). Seemingly, Shenzhen city has been successfully following the concept of developing the economy without damaging the environment, a so-called "win-win" strategy. Thus the city raises our particular interest for exploring the development-environment relationship.

Many studies have explored the development-environment relationship. The Environmental Kuznets Curve (EKC) is one hypothesis that has elicited wide attention (Arrow et al., 1995). The EKC concept was strongly put forward in the early 1990s by Grossman and Krueger (1991) as well as in the context of the 1992 World Development Report (Shafik and Bndyopadhyay, 1992). This hypothesis posits an inverted U-shaped relationship between economic growth and environmental degradation (Figure 1). It assumes that environmental degradation increases when per capita income is at a relatively low level, but that it will start to decline when per capita income reaches a certain point, the so-called turning point. Most EKC studies show that the annual income level at the turning point is around 5000 to 8000 USD (Dasgupta et al., 2002). The conventional EKC has elicited many critiques. The arguments mainly focus on assertions that the evidence for the inverted-U shaped relationship applies only to a subset of environmental measures (Stern, 1998), for instance certain conventional pollutants such as suspended particulates and sulphur dioxide (Stern, 1998; Agras and Chapman, 1999; List and Gallet, 1999). Spangenberg (2001) also argues that the EKC pattern might exist, but not for overall environmental pressure. He utilizes an environmental space measure, a more integrative indicator of environmental pressures on a life-cycle wide basis, and concludes that there is no 
indication of an EKC in economic growth and resource consumption relationship.

Dasgupta et al. (2002) and Perman and Sterm (2003) summarize empirical pollution-income relationships with four scenarios, one of them being the conventional EKC scenario (Figure 1). The "new toxics" scenario states that some conventional contaminants might have inverted U-shaped curve due to clean-up activities, but new contaminants replacing them are emerging - overall environmental impact is thus not reduced. The "race to the bottom" scenario posits that the reduced pollution in developed countries was likely achieved through outsourcing dirty production to developing countries. Developing countries thus will be in difficult position to reduce pollution. The "revised EKC" scenario does not deny the EKC curve, but suggests that technological change is shifting the curve downwards and to the left in the course of time. It suggests that environmental improvements are possible in developing countries and that peak levels of environmental degradations will be lower than in developed countries.

In this paper, a standard EKC model (Stern, 2004) is introduced to examine the development-environment relationship in Shenzhen. This paper aims to investigate the interaction of economic growth and environmental quality in the specific context of Shenzhen. We apply the EKC model to 18 pollutants, which are the target monitoring items in China's environmental monitoring system. These pollutants are supposed to indicate the quality of ambient air, river and near shore waters in Shenzhen from 1984 to 2003. The Nemerow index (Nemerow, 1985) is introduced as an integrated indicator 
for overall environmental quality. We hypothesize that an EKC shaped development-environment relationship is possible in Shenzhen.

We first examine the temporal trends of environmental quality and Gross Domestic Product (GDP) in Shenzhen. Then we apply the standard EKC model (Stern, 2004), using per capita income as independent variable and the concentrations of different pollutants or the Nemerow indices as dependent variables. Finally, in the discussion section, we try to explain the observed development-environment relationships in Shenzhen from a systematic point of view.

\section{Economic growth in Shenzhen}

Since Shenzhen was established as a Special Economic Zone (SEZ) in 1980, its GDP has increased by an average annual rate of $32 \%$ and with an industrial growth rate of $49 \%$. Even when the Asian economic crisis slowed growth throughout China, Shenzhen continued to increase its exports by an average of $9 \%$ annually, and showed an annual growth rate of 18.5\% between 1994 and 1999 (Figure 2) (Guo and Li, 2000). By the end of 2003, the total nominal GDP in Shenzhen reached 286 billion RMB (24.7 billion USD). The per capita nominal GDP in the city is over 50,000 RMB (6500 USD), and the per capita annual income is around 25,900 RMB (3100 USD), which is about twice as high as the nation-wide average.

As the first SEZ, Shenzhen gained a favorable tax policy and investments from the central government to foster its economic growth. Also, the geographic advantage of being a port city and bordering on Hong Kong enabled the city to attract large amounts of foreign direct investment. Many industries in Hong Kong were re-located 
to Shenzhen in order to take advantage of low wages and tax incentives. Towards the end of 2001, over 70 countries and regions had invested in 27,030 projects in Shenzhen (Shenzhen Municipal Government, 2004).

According to national statistics from 1990 to 2003, the major contributing sectors to GDP growth in Shenzhen are the secondary and the tertiary sectors of industry accounting for respectively $53 \%$ and $45 \%$ of the city's total GDP. The primary sector of industry only accounts for 1 to $2 \%$ of the total GDP. The pillar industries of the city are computers and software, information technology, microelectronics and components, video and audio products, and electro-mechanical integration (Shenzhen Municipal Government, 2004). Meanwhile, the industrialization has also facilitated urbanization. Shenzhen has expanded in size from $3 \mathrm{~km}^{2}$ in the beginning of SEZ's establishment to $180 \mathrm{~km}^{2}$ in 2003 (China's Economic Network, 2004).

\section{The environmental quality trends over time}

To evaluate the overall environmental quality, we have used the Nemerow index, which reflects both maximum and average values of pollutants' concentrations relative to their objective levels:

$$
I=\sqrt{\frac{\operatorname{MaxI}_{i}^{2}+\operatorname{AvgI}_{i}^{2}}{2}}
$$

where $I_{i}$ is the pollution index relating the observed concentration $C_{i}$ of pollutant $i$ with its objective concentration $\mathrm{S}_{\mathrm{i}}, \mathrm{I}_{\mathrm{i}}=\mathrm{C}_{\mathrm{i}} / \mathrm{S}_{\mathrm{i}}, \operatorname{MaxI}_{\mathrm{i}}$ is the maximum value of the all indices $\mathrm{I}_{\mathrm{i}}$, and Ave $_{\mathrm{i}}$ is the average of all indices. If $\mathrm{I}>1$, the overall environmental quality does not comply with objectives, whereas if $\mathrm{I}<1$, the quality is better than the set objective.

In order to show the pollutants that most significantly reduce the overall 
environmental quality (in the sense of violating their objective levels), we calculate the percentages $\mathrm{K}_{\mathrm{i}}$ that each polluting substance contributes to the summed pollution index of all pollutant with the following equation:

$$
\mathrm{K}_{\mathrm{i}}=\mathrm{I}_{\mathrm{i}} / \mathrm{I}_{0}
$$

where is $\mathrm{I}_{\mathrm{i}}=\mathrm{C}_{\mathrm{i}} / \mathrm{S}_{\mathrm{i}}$ (as in Equation 1) and $\mathrm{I}_{0}=\sum_{\mathrm{i}} \mathrm{I}_{\mathrm{i}}$.

\subsection{Ambient air quality}

Three major air pollutants are monitored in Shenzhen: Total Suspended Particulates (TSP; with the maximum size of 20 micron in aerodynamic diameter), $\mathrm{SO}_{2}$, and $\mathrm{NO}_{\mathrm{x}}$. The air monitor network comprises nine sampling points distributed around the city. Data are obtained through an automatic monitoring system. The values used in this paper are annual daily average values (SZEMC, 2000).

From 1989 to 2003, Nemerow index comprised of TSP, $\mathrm{SO}_{2}$, and $\mathrm{NO}_{\mathrm{x}}$ maintains a level lower than the critical value I=1 (Figure 3), indicating that overall air quality in Shenzhen complied with the set municipality objective (the second class standard for national ambient air quality). The air Nemerow index did not show significant change in the ambient air quality in Shenzhen. However, relative contributions of individual pollutants have been shifting (Figure 4): $\mathrm{NO}_{\mathrm{x}}$ is becoming increasingly dominant while TSP is declining.

3.2 Water quality in the major rivers 
Four major rivers in the city, the Shenzhen, Buji, Dasha and Guanlan Rivers, are studied here. The watersheds of the first three rivers are located mostly inside the Special Economic Zone (SEZ), and the last one is outside of the SEZ border. More than 10 variables related to water quality are monitored: $\mathrm{BOD}_{5}$, dissolved oxygen (the inverse of this indicator is used in the following analyses as large values indicate good environmental quality), $\mathrm{COD}_{\mathrm{Mn}}$, Total Phosphate (TP), $\mathrm{CN}^{-}, \mathrm{Pb}, \mathrm{Cd}, \mathrm{As}, \mathrm{Cr}^{6+}$, Total Petroleum Hydrocarbon (TPH), and Total Nitrogen (TN). Sampling takes place three times per year. We exclude total nitrogen from our analysis due to data inconsistencies. The water quality objective chosen is the third class of national standard for surface water, as set by State Environmental Protection Agency in China.

During the past decades, water quality in four studied rivers first deteriorated and then started to improve (Figure 5). The Nemerow indices displayed high values in all rivers (Figure 5). Water quality was the worst in the Buji River; in 1994, its Nemerow index was as high as 70 . Other three rivers were in slightly better situation, but their Nemerow indices were nevertheless well above the critical value $\mathrm{I}=1$. Thus, the rivers in Shenzhen have been seriously polluted. However, all rivers have had substantial abatement of pollution since the mid or late 1990s.

Among nine pollutants in rivers, $\mathrm{TPH}, \mathrm{TP}, \mathrm{BOD}_{5}$ and $\mathrm{COD}_{\mathrm{Mn}}$ are the major pollutants (Figure 6). TPH used to be a dominant river water pollutant, but more recently TP, $\mathrm{BOD}_{5}$ and $\mathrm{COD}_{\mathrm{Mn}}$ have become continusouly increasing. The pollution shares of $\mathrm{CN}^{-}$, $\mathrm{Pb}, \mathrm{Cd}, \mathrm{As}$, and $\mathrm{Cr}^{6+}$, which usually originate from industrial sources, are mostly negligible. However, in the Dasha River, a visible share of $\mathrm{CN}^{-}$pollution persists 
(Figure 6).

\subsection{The near-shore waters quality}

In this section, we look at the near-shore water quality in the Shenzhen Bay. Sampling points are placed at estuaries of major rivers along the shoreline. The water is sampled twice each month in the months of April, July and December. The eastern side of the bay should comply with the second level national seawater standard whereas the less strict third level standard is applied on the western side where extensive development has been taking place. The indicators monitored in the near-shore waters are Inorganic Nitrogen, Phosphate, Total Petroleum Hydrocarbon (TPH), $\mathrm{COD}_{\mathrm{Mn}}, \mathrm{Hg}, \mathrm{Cu}, \mathrm{Pb}, \mathrm{Cd}, \mathrm{pH}$ value, and Suspended Solids (SS).

The water quality of the eastern side is almost constant (Figure 7), and the Nemerow pollution index shows that the water quality on the eastern side complies with the standards. On the western side, water quality is worse, despite the less strict standard being applied. Water quality on the western side has been deteriorating, and no longer complies with the objectives. The major pollutants in the western side are Inorganic Nitrogen and TP (Figure 8).

\section{Economic framework}

We introduce the economic dimension to our analyses by using the per capita GDP to indicate the level of economic growth in Shenzhen. We use the following regression model to describe the link between economic growth and environmental quality:

$$
\ln \left(\mathrm{I}_{\mathrm{t}}\right)=\mathrm{b}_{0}+\mathrm{b}_{1} \ln \left(\mathrm{GDP}_{\mathrm{t}} / \mathrm{P}_{\mathrm{t}}\right)+\mathrm{b}_{2}\left[\ln \left(\mathrm{GDP}_{\mathrm{t}} / \mathrm{P}_{\mathrm{t}}\right)\right]^{2}
$$


where concentration of a pollutant is treated as the dependent variable and per capita GDP is treated as the independent variable. I is a pollution index, $\mathrm{P}$ is population size, and $\mathrm{ln}$ indicates natural logarithm transformation. Notice that no time effects are estimated here as we have only one monotonically increasing time series of GDP. If the regression coefficient $b_{2}$ is negative, equation 3 corresponds to the standard EKC model.

In regression analyses below, we have chosen Nemerow index, an integrative index of different pollutants monitored in Shenzhen, and major pollutants identified in section 3 as the dependent variables $\mathrm{I}_{\mathrm{t}}$. We use real GDP instead of nominal GDP (without the adjustment, the analyses would be distorted by inflation).

\subsection{The regression analysis on ambient air quality}

The dependent variables are Total Suspended Particulates (TSP), $\mathrm{SO}_{2}, \mathrm{NO}_{\mathrm{x}}$ and the Nemerow index. For the Nemerow index, $\mathrm{NO}_{\mathrm{x}}$ and TSP, double log plots show significant declines (Figure 9). None of the regression models have significant curvature, thereby seemingly refuting the EKC hypothesis (Table $1-$ the coefficients corresponding to the square term in equation (3) are not different from zero). However, these pollutants are primarily generated by anthropogenic activities and their levels must have been low when human interventions were low. Therefore, existence of the rising left leg of EKC is a logical necessity, even though there is no observed data to illustrate this part of the curve. Therefore, TSP, $\mathrm{NO}_{\mathrm{x}}$ and Nemerow index actually support the EKC scenario. In contrast, $\mathrm{SO}_{2}$ significantly increased in concentration 
(Figure 9). Thus, EKC does not apply to this pollutant.

\subsection{The regression analysis on river water quality}

We study four dependent variables in each river: Total Petroleum Hydrocarbon (TPH), Total Phosphor (TP), $\mathrm{BOD}_{5}$, and the Nemerow index. For the Nemerow index, the log-log plot clearly shows an inverted U shaped relationship in three out of four rivers (Figure 10), and coefficients of the models corresponding to the square term in equation (3) are significantly less than 0 (Table 2). EKC thus applies in these rivers. In the fourth river, however, overall water quality has significantly declined over the study period, and EKC does not hold. The results are similar for the models with TPH as the dependent variable (Figure 11). This is due to the fact that TPH has been the dominant contributor to the Nemerow index.

Overall patterns for Total phosphorous (TP) and $\mathrm{BOD}_{5}$ are different from those mentioned above. For TP in the Shenzhen River, there is a significant declining curve. As discussed earlier, this supports EKC assuming that the rising left leg of the curve is unobserved. In the Dasha River, TP has increased, but the coefficient corresponding to the square term in equation (3) is significantly different from zero. This suggests that TP has reached its top level in the Dasha River. However, there is no clear sign of downward trend yet, and the support to EKC remains ambiguous. Regression models for both Buji and Guanlan Rivers are far from supporting EKC phenomena. Instead, during the studying period, TP concentration is increasing significantly in both rivers, with no sign of levelling off (Figure 12). The overall patterns are similar for $\mathrm{BOD}_{5}$. The declining trend in the Shenzhen River supports EKC. For other rivers, EKC is 
refuted as $\mathrm{BOD}_{5}$ tends to increase. In the Guanlan River, we actually observe a $\mathrm{U}$ shaped relationship, or an opposite EKC curve (Figure 13).

\section{3. The regression analysis on near-shore waters}

Near-shore waters refer here to the western side of Shenzhen Bay only. The dependent variables in the regressions are inorganic nitrogen, phosphate and the Nemerow index. The log-log plots show water quality declining with economic development, and therefore no support for an EKC relationship (Figure 14). As the coefficients of all three models have no significant curvature (Table 3 ), there is no indication of these trends levelling off.

\section{Discussion}

We have studied the environment-development relationship in Shenzhen, the first Special Economic Zone in China, using data across a large number of pollutants describing different components of the environment. In comparison to most other EKC studies, the time frame of our study is relatively short and we focus on just one area, but on the other hand, our environmental data are of good resolution and quality.

Our results show four types of environment-development relationships: EKC, downward pattern, upward pattern and inverted EKC. Classic EKC pattern is observed in all but one study river for overall pollution. Downward pattern — environmental quality monotonically increasing with development - is recorded for $\mathrm{NO}_{\mathrm{X}}$ and Total Suspended Particulates (TSP) in the ambient air, and $\mathrm{BOD}_{5}$ and Total Phosphorous (TP) in the Shenzhen River. As discussed earlier, the downward pattern may still support the existence of EKC: downward pattern is expected when the EKC holds, but the time 
frame of observations may not sufficient enough to reveal the upward part of the curve. Upward pattern - monotonic environmental deterioration - is observed for $\mathrm{SO}_{2}$ in the ambient air, all pollutants in one of the studied rivers and for many pollutants in two other rivers, and for all pollutants in the near-shore waters. An inverted EKC pattern is observed once, for $\mathrm{BOD}_{5}$ in the Guanlan River. Notice that the upward pattern does not necessarily disprove the $\mathrm{EKC} \mathrm{—} \mathrm{it} \mathrm{only} \mathrm{proves} \mathrm{that} \mathrm{EKC}$ does not hold for the observed range of GDP. Thus, in interpreting empirical environment-development relationships, it is important to realize that the time frame of observations may have decisive effects: we may miss either the rising or the decreasing leg of the curve.

In short, the environmental Kuznets curve is but one of several possible patterns describing the relationship between development and the environment. However, a closer look at the results from Shenzhen reveals an interesting pattern: production-related pollutants in rivers (Figure 10) likely support EKC, but consumption-related pollutants (Figures 9 and 14) do not support EKC. We elaborate on this point below.

\subsection{Production-induced pollutants support EKC}

Why would only rivers inside the Special Economic Zone (SEZ) display EKC? Figure 15 suggests how river water quality and economic growth have been interacting. Once environmental quality deteriorates, the local government has to strengthen environmental regulation, often by allocating more funds to improve the common property resources (e.g., river water), or by enforcing strict "Command and Do" 
regulation on polluting enterprises and by economic instruments. Statistics shows that untill July of 2003, over 180 factories in Shenzhen have been forced to meet the established emission standards, total fines collected from industry exceed 8,240,000 RMB (about 1.0 million USD), and companies have invested over 24,760,000 RMB (about 3.0 million USD) in building treatment facilities (Shenzhen Commercial Daily, 2003). Because, treatment activities may increase production costs. This provides an incentive for moving production to places where environmental regulation is less stringent. This response to environmental regulation by enterprises may to a large extent weaken the government's determination to strictly enforce environmental regulations, because once those big industrial players move out of the SEZ, it will outsource local GDP as well. Technological innovation could also play some roles in reducing emission (Dinda, 2004). However, with a relatively short time period and a geographically restrained system such as river, it appears as a much less influential factor.

Given the arguments above, the differences between the rivers situated inside and outside the SEZ are twofold. First, the intensity of clean-up actions differ: the Shenzhen River, which is regarded as the mother river of the city, has had the most intensive clean-up actions among all, whereas the Guanlan River that is situated outside of the SEZ has had the least. The second main difference is the number of polluting companies. For companies, together with internalized treatment costs, their labour costs and land renting costs will increase following the economic growth. Thus some companies either have to shrink their production scale, or relocate their 
production outside the SEZ for lower costs. Due to the same consideration, new companies tend to settle down outside of the SEZ instead of inside. The overall response from companies will result in fewer emissions inside the SEZ. All in all, it seems that pollution outsourcing and river clean-up actions, driven both by market mechanism and by government enforcement, induce the emergence of EKC in the river system. This further explains why total petroleum hydrocarbon (TPH) - a production-induced pollutant (State Environmental Protection Agency, 2002) - in the rivers inside the SEZ support EKC, but TPH in the Guanlan River outside the SEZ does not. Finally, the downward patterns of total suspended particles and $\mathrm{NO}_{\mathrm{x}}$ could also be explained by the government's environmental regulations on oil and coal burning industries in Shenzhen.

\subsection{Consumption-related pollutants do not support EKC}

Our results show an important feature: most pollutants related to organic pollution such as $\mathrm{BOD}_{5}$, total phosphorus, inorganic nitrogen and phosphate show an upward environment-development relationship. These pollutants originate mostly from consumption behaviours including residential emissions and emissions from the service sector. Figure 16 illustrates how consumption behaviour interacts with the environment and economy. As a high-income city, Shenzhen has been attracting a huge amount of immigrants who are mostly young and unskilled workers from the interior parts of China. They are poorly paid and can only afford cheap accommodations in the so-called villages within the city (VWC). There are hundreds of such VWCs that can

supply around 1,350,000 cheap rooms for 5,000,000 immigrants (Shenzhen Academy 
of Social Science, 2004). Since migration is extensive - around 1.21 million people have moved in between 1999 and 2003 (Shenzhen Statistics Bureau, 1999-2003) sufficient sewage treatment systems and other sanitation infrastructure could not be built during such a short period to relieve residential emission. These residential pollutants mostly end up in city's rivers and the sea, and contribute to deteriorating water quality. Moreover, higher income will lead to further growth in the service sector that is replacing industrial sector in the city: richer citizens can afford to consume more luxury goods and services, typically in the catering sector. Thus the service sector has an increasing contribution to the accumulation of organic pollution. In summary, upward patterns are due to increasing ecological footprints and the lack of effective environmental treatment on consumption-induced waste. This indirectly supports the notion that EKC is generated by environmental regulation. Given that no effective regulation is in place, the environment-development relationship may be consistently upward. Figure 16 also implies that citizen's demand for a good environment adds pressure for the government to pursue effective regulation on consumption-induced wastes.

The upward pattern in $\mathrm{SO}_{2}$ model tells a different story. As $\mathrm{SO}_{2}$ is known as a pollutant that is readily transported over long distances, the increasing trend of $\mathrm{SO}_{2}$ in Shenzhen is likely influenced by sources from the vicinity or other parts of the country. Indeed, acid rain is wide-spread in China, with Guangdong province (in which Shenzhen is located) having one of the most serious problems.

\section{Conclusions}


EKC is only one of many types of environment-development relationships in Shenzhen, China. Upward pattern, downward pattern and inverted EKC are three other featured relationships. The general pattern is that production-induced pollutants tend to support EKC while consumption-induced pollutants do not. For rivers, the emergence of EKC is mainly due to the relocation of pollution and direct clean-up actions, which are driven by the market and by government interventions. For organic pollutants, the robust upward pattern is due to the scarcity of sewage treatment systems and other public sanitation facilities. However, the income elasticity of environmental quality demand is adding pressures for good environmental governance. Once regulatory regimes are put in place, upward patterns for consumption pollutants are expected to turn down. As the final note, we emphasize that the time frame of observations may have decisive effects when interpreting empirical environment-development relationships.

\section{Acknowledgements}

Xiaozi Liu would like to thank Dr. Gerhard Heilig for supervision and Mr. Larry Willmore for helpful advice during Young Scientist Summer Program at IIASA. Xiaozi Liu would also like to express her special thanks to her M.Sc. supervisors, Prof. Bengt Nihlgard in Lund and Dr. Jan Sendzimir at IIASA, for their comments and guidance. We thank XXX for kindly checking the language and Dr. Jerry Boese and three anonymous referees for helpful comments on the manuscript. The economic support by FORMAS and LUMES is gratefully acknowledged. 


\section{References}

Agras, J. and Chapman, D. 1999. A dynamic approach to the environmental Kuznets hypothesis. Ecol. Econ. 28:267-278.

Arrow, K., Bolin, B., Costanza, R., Dasgupta, P., Folke, C., Holling, C.S., Jansson, B.O., Levin, S., Mäler, K.G., Perrings C., and Pimentel, D. 1995. Economic growth, carrying capacity, and the environment. Ecol. Eco. 15:91-95.

Dasgupta, S., Laplante, B., Wang, H. and Wheeler, D. 2002. Confronting the environmental Kuznets curve. J. Econ. Perspect. 16:147-168.

Dinda, S. 2004. Environmental Kuznets curve hypothesis: a survey. Ecol. Econ. 49:431-455.

Grossman, G. M., and Krueger, A. B. 1991. Environmental impacts of a North American Free Trade Agreement. National Bureau of Economic Research. Working Paper 3914, NBER, Cambridge, MA.

Guo, R. and Li, Z., 2000. Shenzhen: retaining the lead in Growth. World Economic Forum. http://www.weforum.org.

List, J. A. and Gallet, C.A. 1999. The environmental Kuznets curve: does one size fit all? Ecol. Econ. 31:409-424.

Liu, J. and Diamond, J., 2005. China's environment in a globalizing world. Nature 435:1179-1186.

Nemerow, N.L., 1985. Stream, Lake, Estuary, and Ocean Pollution. Van Nostrand Reinhold, New York. 
NSB (National Statistics Bureau) 1989-2003. China's National Statistics Yearbook. National Statistics Bureau, China.

Perman, R., and Stern, D. I., 2003. Evidence from panel unit root and cointegration tests that the environmental Kuznets curve does not exist. Aust. J. Agr. Resour. Econ. 47:325-347.

Sen, G. 2001. Post-reform China and the international economy: economic change and liberalization under sovereign control. Department of International Relations, London School of Economics, http://www.theglobalsite.ac.uk/press/103sen.pdf.

Spangenberg, J.H. 2001. The environmental Kuznets curve: a methodological artefact? Popul. Envir.on. 23:175-191.

State Environmental Protection Agency 2002.Technical Specifications Requirements for Monitoring of Surface Water and Waster Water (HJ/T 91-2002). State Environmental Protection Agency, China.

Shafik, N. and Bandyopadhyay, S. 1992. Economic Growth and Environmental Quality: Time Series and Cross-Country Evidence. Background Paper for the World Development Report 1992, World Bank, Washington, DC.

Shenzhen Academy of Social Science 2004. Shenzhen Lan Pi Shu (The Blue Book of Shenzhen). Social Scientific Documentation Publishing House, Beijing, China.(in Chinese)

Shenzhen Commercial Daily 2003 (October 11). Shenzhen becomes the first city in the nation that has achieved the overall industrial pollution emission objectives. 
http://www.shenzhen.net.cn/shishi/s2/200310110013.htm

Shenzhen Municipal Government 2004. Shenzhen government online: industry information. http://www.sz.gov.cn/english/gs.

Shenzhen Statistics Bureau 1999-2003. Shenzhen Statistics Yearbook. Shenzhen Statistics Bureau, China.

Stern, D.I. 1998. Progress on the environmental Kuznets curve? Environ. Dev. Econ. 3:173-196.

Stern, D.I. 2004. The rise and fall of environmental Kuznets curve. J. World Dev. 32:1419-1439.

SZEMC (Shenzhen Environmental Monitoring Center) 2000. The introduction of the ambient air monitoring system in Shenzhen. Shenzhen Environmental Monitoring Center, China. www.api-shenzhen.gov.cn.

UNEP 2002. Adult Award Winner in 2002: Municipal Government of Shenzhen. Global 500 forum. http://www.global500.org. 


\section{Tables}

Table 1. Regression analyses on air quality in Shenzhen. $b_{0}-b_{2}$ refer to the coefficients of equation (3); none of these is significantly different from 0 . The overall significance of the model is given by p. Error d.f. $=7$ in all regressions.

\begin{tabular}{lcccccc}
\hline Dependent variable & $\mathrm{R}^{2}$ & $\mathrm{~F}$ & $\mathrm{p}$ & $\mathrm{b}_{0}$ & $\mathrm{~b}_{1}$ & $\mathrm{~b}_{2}$ \\
\hline Nemerow & 0.50 & 5.4 & 0.038 & 20.9 & -3.90 & 0.175 \\
$\mathrm{NO}_{\mathrm{x}}$ & 0.46 & 4.9 & 0.047 & 22.3 & -4.14 & 0.187 \\
$\mathrm{TSP}$ & 0.81 & 20.1 & 0.001 & -9.27 & 2.43 & -0.158 \\
$\mathrm{SO}_{2}$ & 0.61 & 8.2 & 0.015 & -8.26 & -0.234 & 0.076 \\
\hline
\end{tabular}


Table 2. Regression analyses on river water quality in Shenzhen. $b_{0}-b_{2}$ refer to the coefficients of equation (3); boldface indicates coefficients that are significantly different from 0 . The overall significance of the model is given by . Error d.f. $=9$ in all regressions.

\begin{tabular}{lcccccc}
\hline $\begin{array}{l}\text { River/dependent } \\
\text { variable }\end{array}$ & $\mathrm{R}^{2}$ & $\mathrm{~F}$ & $\mathrm{p}$ & $\mathrm{b}_{0}$ & $\mathrm{~b}_{1}$ & $\mathrm{~b}_{2}$ \\
\hline $\begin{array}{c}\text { Shenzhen River } \\
\text { Nemerow }\end{array}$ & 0.66 & 11.8 & 0.003 & $\mathbf{- 1 3 0}$ & $\mathbf{2 7 . 6}$ & $\mathbf{- 1 . 4 2}$ \\
TPH & 0.56 & 7.9 & 0.010 & $\mathbf{- 2 0 9}$ & $\mathbf{4 4 . 1}$ & $\mathbf{- 2 . 3}$ \\
TP & 0.82 & 26.7 & $<0.001$ & $\mathbf{3 5 . 2}$ & -6.11 & 0.280 \\
BOD & 0.51 & 6.7 & 0.016 & -27.5 & 6.28 & -0.334 \\
\hline Buji River & & & & & & \\
Nemerow & 0.77 & 19.1 & $<0.001$ & $\mathbf{- 2 0 4}$ & $\mathbf{4 1 . 7}$ & $\mathbf{- 2 . 0 9}$ \\
TPH & 0.71 & 14.5 & 0.002 & $\mathbf{- 2 3 2}$ & $\mathbf{4 7 . 6}$ & $\mathbf{- 2 . 4 0}$ \\
TP & 0.80 & 23.4 & $<0.001$ & 22.6 & -4.52 & 0.249 \\
BOD 5 & 0.51 & 6.8 & 0.016 & -4.27 & 0.766 & -0.012 \\
\hline Nemerow & 0.80 & 23.1 & $<0.001$ & $\mathbf{- 9 9 . 0}$ & $\mathbf{1 9 . 6}$ & $\mathbf{- 0 . 9 3 9}$ \\
TPH & 0.48 & 6.1 & 0.020 & $\mathbf{- 2 1 6}$ & $\mathbf{4 3 . 9}$ & $\mathbf{- 2 . 2 0}$ \\
TP & 0.95 & 107 & $<0.001$ & $\mathbf{- 6 5 . 6}$ & $\mathbf{1 2 . 5}$ & $\mathbf{- 0 . 5 6 8}$ \\
BOD & 0.81 & 24.0 & $<0.001$ & -12.0 & 1.72 & -0.041 \\
\hline Dasha River & & & & & & \\
Nemerow & 0.57 & 8.3 & 0.009 & -18.8 & 2.84 & -0.074 \\
TPH & 0.49 & 6.2 & 0.021 & -26.7 & 4.64 & -0.173 \\
P & 0.84 & 29.3 & $<0.001$ & -26.1 & 2.69 & 0.008 \\
BOD 5 & 0.93 & 75.5 & $<0.001$ & $\mathbf{8 5 . 4}$ & $\mathbf{- 1 8 . 5}$ & $\mathbf{1 . 0 0}$ \\
\hline Guanlan River & & & & & &
\end{tabular}


Table 3. Regression analyses on near-shore water quality in the western side of Shenzhen. $b_{0}-b_{2}$ refer to the coefficients of equation (3); none of these is significantly different from 0 . The overall significance of the model is given by . Error d.f. $=7$ in regressions for Nemerow and phosphorus, 6 for nitrogen.

\begin{tabular}{lcccccc}
\hline Dependent variable & $\mathrm{R}^{2}$ & $\mathrm{~F}$ & $\mathrm{p}$ & $\mathrm{b}_{0}$ & $\mathrm{~b}_{1}$ & $\mathrm{~b}_{2}$ \\
\hline Nemerow & 0.64 & 8.9 & 0.012 & -1.88 & -0.651 & 0.085 \\
Inorganic N & 0.58 & 5.8 & 0.050 & 101 & -20.1 & 1.01 \\
Phosphorus & 0.50 & 5.5 & 0.036 & 104 & -21.3 & 1.09 \\
\hline
\end{tabular}




\section{Figure captions}

Figure 1. Environmental Kuznets Curve (EKC): alternative views. Redrawn from Dasgupta et al. (2002) and Perman and Stern (2003).

Figure 2. Per capita Gross Domestic Product (GDP) and per capita income in Shenzhen. The data are compiled from Shenzhen Statistics Yearbooks in 1990-2003. Both per capita GDP and income are calculated in the current price.

Figure 3. Air quality for $\mathrm{SO}_{2}, \mathrm{NO}_{\mathrm{x}}$ and Total Suspended Particles (TSP). Air quality is expressed as indices calculated as ratios between average concentration of a pollutant and its objective level (index below 1 thus implies that the objective is met). In addition, Nemerow index describing overall air quality is displayed. The indices are calculated from raw monitoring data by Shenzhen Environmental Protection Agency (partly retrievable at http://www.sepa.gov.cn).

Figure 4. The relative contributions of each pollutant to the total air pollution index in Shenzhen. TSP=Total Suspended Particulates.

Figure 5. The overall water quality trends over time in different rivers of Shenzhen. Source: Shenzhen Environmental Monitoring Center. Note that there are no data for the period 1991-1993.

Figure 6. The relative contributions of each pollutant to the total pollution index in four rivers in Shenzhen. TPH=Total Petroleum Hydrocarbon, TP=total phosphorus. DO and $\mathrm{pH}$ are excluded from our assessments.

Figure 7. Trends of the near-shore water quality over time in Shenzhen. The index used in the Nemerow index describing overall environmental quality.

Figure 8 . The relative contributions of polluting substances to the total pollution index in the near-shore waters of Shenzhen (western side).

Figure 9. The relationship between per capita GDP and air quality in Shenzhen. The curves show quadratic regression models fitted to the data on log-log scale.

Figure 10. The relationship between per capita GDP and Nemerow index that measures overall environmental quality in Shenzhen rivers. The curves show quadratic regression models fitted to the data on log-log scale.

Figure 11. The relationship between per capita GDP and Total Petroleum Hydrocarbon (TPH) in Shenzhen rivers. The curves show quadratic regression models fitted to the data on log-log scale. 
Figure 12. The relationship between per capita GDP and Total Phosphorus in Shenzhen rivers. The curves show quadratic regression models fitted to the data on log-log scale.

Figure 14. The relationship between per capita GDP and near-shore water quality in the western side of Shenzhen. The curves show quadratic regression models fitted to the data on log-log scale.

Figure 15. Causal loop diagram illustrating production-induced pollution (produced with Vensim3.0).

Figure 16. Causal loop diagram illustrating consumption-induced emissions (produced with Vensim3.0). 